Revista Iberoamericana, Vol. LXXVIII, Núm. 240, Julio-Septiembre 2012, 555-566

\title{
CONTINUIDADES Y DIFERENCIAS ENSAYÍSTICAS EN \\ MY OWN PRIVATE CUBA: ESSAYS ON CUBAN LITERATURE AND CULTURE DE GUSTAVO PÉREZ FIRMAT
}

\author{
POR \\ JOY LANDEIRA \\ University of Northern Colorado
}

Como ensayista, Gustavo Pérez Firmat sigue dos pautas. Una, la más tradicional, es la ruta académica establecida en las grandes universidades estadounidenses como la University of Michigan, donde se doctoró en literatura comparada con una disertación sobre la novela vanguardista española, y como Duke University en Carolina del Norte y Columbia en Nueva York, donde ha ejercido su honrada carrera como profesor de literatura española y comparada. Como representante de la academia escolástica, se entrenó en las tradiciones ensayísticas de a principios del siglo veinte de España promulgadas por ensayistas como Ortega y Gasset, Azorín, y los poetas profesores de la Generación del '27 -Dámaso Alonso, Pedro Salinas y Jorge Guillén, entre otros-. Su formación española como académico literato forma la base profesional de su labor como investigador. Por este lado de su preparación académica, bien sabe documentar y formular un ensayo clásico usando la metodología tradicional del trabajo investigativo norteamericano universitario. En esta veta podemos categorizar los trabajos suyos: Idle Fictions: The Hispanic Vanguard Novel 1926-1934; Literature and Liminality: Festive Readings in the Hispanic Tradition; y los ensayos de Tongue Ties sobre George Santayana, Pedro Salinas y Luis Cernuda. Con estas obras se afirma su habilidad de continuar las tradiciones ensayísticas de la academia escolástica peninsular y norteamericana.

Por otro lado, y en años más recientes, la producción ensayística de Pérez Firmat ha empezado a diferenciarse de lo tradicional y a adquirir contornos más híbridos. Él empieza a explorar otras posibilidades del género, popularizándolo con temas culturales, y, en el proceso, invierte la metodología tradicional del trabajo investigativo norteamericano, aproximándose a otro género híbrido, el de la crónica urbana, incorporando nociones reconocidas en La expresión americana, del cubano Lezama Lima, y de otros ensayistas cubano-americanos como Román de la Campa. El libro más conocido de Pérez Firmat, Life on the Hyphen: The Cuban-American Way (1994), que fue auto-traducido a Vidas en vilo: la cultura cubanoamericana (2000), propone su concepto del "hyphen" -el espacio de entre dos mundos que los exiliados cubanos experimentan al hacer su nueva 
identidad urbana americana en los Estados Unidos. Tal y como su vida en vilo es una combinación de lo cubano y lo americano (“Cuban-American”), los ensayos de esta nueva índole exploran la vida desde otra orilla ideológica, donde el "YO" subjetivo es esencial para definir al ensayista mismo y su manera de vivir. Los ensayos de The Cuban Condition: Translation and Identity in Modern Cuban Literature; My Own Private Cuba: Essays on Cuban Literature and Culture; y el ensayo-memoir Next Year in Cuba: A Cubano's Coming-of-Age in America incorporan el "yo" y la búsqueda de identidad personal como elementos céntricos del quehacer literario.

Esta nueva presencia cubana y cubano-americana en el ensayo perezfirmatiano le da un nuevo vigor. No es solo una continuación de la tradición académica peninsular, ni es la continuidad de lo cubano. El "hyphen" que Pérez Firmat ha definido como céntrico a la vida suya y de los cubanoamericanos de su generación también caracteriza el ensayo mismo en sus manos. El género es híbrido: en parte penínsular tradicional, en parte cubano tradicional; como fruta de esta hibridización crece una nueva forma que da una marca específica a sus ensayos que refleja la literatura y la cultura, lo español, lo cubano y lo cubano-americano, encarnando en sus ensayos lo que significa ser ensayista en las Américas.

En un breve artículo de mediados de los años sesenta del siglo pasado, titulado "La significación del ensayista en las Américas”, un antiguo profesor mío concuerda con Robert G. Mead, afirmando que el espíritu del ensayo, "es comunicar los conceptos o meditaciones personales de una manera lírica”, y que "esto ha sido siempre una tarea de participación americanista” (Onís 445). Acaba por citar directamente la Breve historia del ensayo hispanoamericano de Mead:

[...] la obra de los mejores ensayistas iberoamericanos es una prueba elocuente de que comparten el noble sueño de Pedro Henríquez Ureña y Alfonso Reyes en hacer de América el teatro de mejores experiencias humanas...Dudamos de que ni los estorbos y enojos políticos y sociales presentes, ni las corrientes anti-intelectualistas de hoy, logren impedir de un modo permanente la contribución de los ensayistas actuales y futuros, maduros y jóvenes, a la realización de tan generoso sueño. Al contrario, nos parece que los tiempos de crisis que prevalecen en tantos de nuestros países han creado un ambiente singularmente fértil para el desenvolvimiento de estos críticos y comentaristas de la cultura en sus transformaciones. (127)

Antes de ponernos nosotros también de acuerdo con tales “elocuentes” palabras o mejor dicho grandilocuentes, hay que examinar a fondo este "noble" y "generoso sueño" de hacer de América el "teatro de mejores experiencias humanas". La triste realidad es que en 1956 Mead no presenciaba los muchos "estorbos y enojos políticos y sociales" que iban a impedir tal sueño. Si enfocamos solamente la región caribeña, hay que admitir que no se ha logrado la distinción de ser un "teatro de mejores experiencias

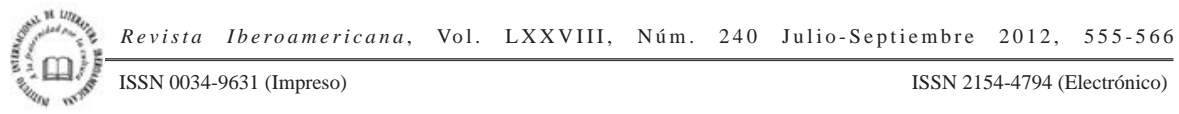


humanas". Ahora, a fines del siglo xx y en la primera década del xxI, vemos que, a diferencia de los ideales cantados por de Onís y Mead, el ensayista ha dejado de soñar con tal teatro de mejores experiencias humanas que, al fin y al cabo, siempre ha sido precisamente esto: un sueño y un teatro. Los ensayistas en general y los ensayistas cubanos y cubano-americanos en particular han pasado por tiempos de crisis que han sido fértiles no para cultivar sueños teatrales, sino para enfrentarse con "la cultura en sus transformaciones”. Al igual que el tema de nuestro número especial de la Revista Iberoamericana, "El ensayo de fines del siglo veinte en América Latina y el Caribe: Continuidades y diferencias", vemos que para fines del siglo xx, hay continuidades -el ensayista latinoamericano y caribeño mantiene su empeño americanista de comunicar "los conceptos o mediaciones personales de una manera lírica” y continúa enfocando en "la cultura en sus transformaciones". También hay diferencias -la significación y el significado del ensayo no es de aferrarse a las tradiciones peninsulares ni de soñar, sino de percibir y, aún más importante, de moldear esta cultura en sus transformaciones. A diferencia del espíritu de mediados del xx, el ensayista deja de soñar.

No pretende este artículo puntualizar el desarrollo de cincuenta años de ensayo cubano en la isla ni el del exilio. "El tema es, creo yo, inagotable" son las palabras de uno de los más conocidos ensayistas españoles de siglo xx, a quien Pérez Firmat ha estudiado a fondo, José Ortega y Gasset (Notas 46). Podríamos asignarlas a cualquier ensayo, dado que el espíritu de este género mismo es limitarse, según muestra José Luis Gómez-Martínez en el capítulo "El ensayo no pretende ser exhaustivo", de su libro Teoría del ensayo (33-34). La brevedad y "el no pretender decir todo sobre el tema tratado" (34) no son características fallidas del ensayo, sino una manera de profundizar en un enfoque, y así abrir un diálogo con el lector. Al concluir su colección Estudios sobre el amor, cuyo tema es igualmente inagotable, Ortega declara, "Al terminar este ensayo me importa recordar que he intentado en él exclusivamente describir un solo estadio del gran proceso amoroso" (133). Para parafrasearlo, añado que el intento del presente ensayo es describir un solo estadio del gran proceso ensayístico americanista, centrándonos solamente en el ensayista cubano-americano Gustavo Pérez Firmat.

Al enfrentarse con el problema de su cultura y de su propia vida en transición con el exilio de Cuba a los Estados Unidos, Gustavo Pérez Firmat ha empleado varios géneros literarios: la autobiografía, la poesía y la novela. Recientemente en su "Recovery Journal”, Scar Tissue, logra combinar la poesía con la prosa en un diario que enfoca el tema del cáncer. El uso de estos géneros creativos es típico para revelarse y sincerarse. De modo más original y en cierto sentido controversial, Pérez Firmat se ha apropiado hasta del ensayo literario y cultural como una expresión personal de su identidad, cruzando la frontera entre el ensayo estrictamente de investigación académica y el relato personal. El título mismo de una de las colecciones da testimonio a la personalización del ensayo: My Own Private Cuba, mientras que el subtítulo, Essays on Cuban Literature and

\footnotetext{
Revista Iberoamericana, Vol. LXXVIII, Núm. 240 Julio-Septiembre 2012, 555-566 ISSN 0034-9631 (Impreso) ISSN 2154-4794 (Electrónico)
} 
Culture promete contenido literario y culto sobre Guillén, Carpentier, Mañach y Ortiz. Consciente de borrar las fronteras entre el ensayo académico y el personal, el autor nos dice francamente, "[...] I have not shied away from blurring the boundaries between the scholarly and the personal [...]" (7). Es precisamente este esfumamiento de las fronteras entre géneros, y entre lo académico, lo político y lo personal, que arrima con el quehacer del ensayista, según la definición de Mead, de "comunicar los conceptos o meditaciones personales de una manera lírica” (Mead 127).

La incorporación y la corporalización de su "yo" lo hace ensayista en la veta más tradicional y pura. Admite la presencia del autor mismo; no se aferra a un ascético ni a un antiséptico empirismo científico. Como ensayista, se remonta a la tradición de Michel de Montaigne (1533-92), creador del género ensayístico moderno que data de 1580, fecha de la primera edición de sus Essais, según quien: "es el juicio un instrumento necesario en el examen de toda clase de asuntos, por eso yo lo ejercito en toda ocasión en estos ensayos" (De Democritus et Heraclitus 50). Valga la palabra: es EnsaYO. El ensayista ejerce su YO y su juicio.

La aportación más valiosa del escritor francés es la introducción del “yo” en su creación artística. Montaigne lo señala orgullosamente: "Los autores se comunican con el mundo en extrañas y peculiares formas; yo soy el primero en hacerlo con todo mi ser, como Michel de Montaigne, no como gramático o como poeta, o como jurisconsulto" (364).

En una reseña de otro libro de ensayos culturales de Pérez Firmat, Vidas en vilo: la cultura cubanoamericana (la versión española de Life on the Hyphen: The CubanAmerican Way) Elisabeth Austin declara que este libro es “más personal que empírico”, notando que "alterna entre el rigor académico de la investigación de la historia popular y la glosa personal de esta historia” (122). Es precisamente esta calidad personal la que define el ensayo, en el sentido más estricto de la palabra y en la tradición ensayista montaignana. El ensayo puede abarcar cualquier tema. Elisabeth Austin acaso no aprecie ni entienda a Gustavo Pérez Firmat como ensayista en el enjuiciamiento siguiente:

El volumen abarca áreas que no suelen figurar en este tipo de proyecto -comediantes, chistes populares, la televisión, la música popular miamense y la tradición folklórica cubana- a la vez que ofrece una lectura fácil (para los lectores no familiarizados con la crítica literaria), una narrativa humorística, cuasi-autobiográfica, y un argumento seductivo. Lo que se destaca en este texto es su documentación del desarrollo de una identidad cultural y lingüística cubanoamericana individual: la de su autor Gustavo Pérez Firmat. (123)

Austin claramente cree entender el quehacer de "la crítica literaria” y duda del acierto de Pérez Firmat en cuanto a lo que debe “figurar en este tipo de proyecto”. Quizás debiera ella misma considerar las diferencias que distinguen la crítica literaria del ensayo. El

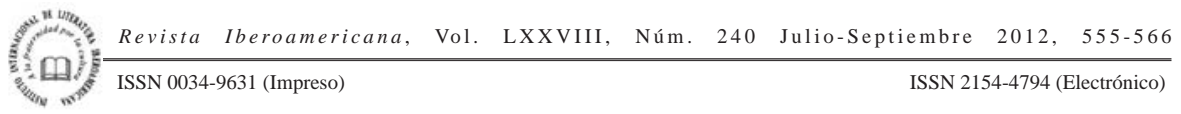


ensayista mismo es quien define su "tipo de proyecto", no el crítico que lo examina. Lo que Austin define como su fuerte, "la índole personal de sus anécdotas y análisis" es lo mismo que distingue "este tipo de proyecto" como libro de ensayos. Gustavo Pérez Firmat mismo ha apuntado su propia presencia. Vemos aquí el colmo de aquella tendencia crítica académica que impone reglas genéricas en busca de "lo académico", en vez de acatar y entender la tradición ensayística. Gracias a autores radicales, en todos los sentidos de la palabra, como Gustavo Pérez Firmat, la tradición del ensayo se mantiene, aunque desconocida y desapercibida por muchos del establecimiento crítico.

La disolución de las demarcaciones genéricas practicada por Pérez Firmat se observa en una serie de técnicas innovadoras y temas característicos. A través del ensayo, Pérez Firmat inventa su propia Cuba, porque su situación verdadera es que, como exiliado, no tiene Cuba. La presencia constante de Cuba en su vida intelectual y el acto de diluir los marcos ensayísticos contrasta con la ausencia física continua de su país natal, cuyas fronteras nunca se disuelven, a pesar de ser, irónicamente, fronteras de agua.

Si nos fijamos en el subtítulo de este volumen de ensayos, "Continuidades y diferencias”, opinamos que el espíritu de continuidad vive en los ensayistas que se empeñan en aplicar su juicio y en escribir ensayos, a pesar de las restricciones del establecimiento crítico, regido ante todo por el claustro universitario. A diferencia de mediados del siglo xx, cuando se enseñaba el ensayo como uno de los cuatro géneros reconocidos, al lado de la narrativa, la poesía y el teatro, hoy en día numerosos críticos no lo admiten, y hay muchos programas universitarios que solo lo enseñan en sus clases de composición básica, mayormente como una manera de practicar la sintaxis y la gramática y no como una manera de ensayar opiniones y observar las transformaciones culturales. La fuerte presencia del "yo" y el estilo personalísimo de los grandes ensayistas es el resultado directo de su habilidad de observar y evaluar las transformaciones culturales desde la perspectiva aguda de alguien que entiende su propia generación y está inmiscuido en las circunstancias de su época, pero que puede, a la vez, ver como su cultura y sus circunstancias continúan y se diferencian de las otras generaciones.

En manos de Pérez Firmat, el ensayo continúa la tradición ensayista cubana establecida a principios del siglo xx por el antropólogo y pionero folclorista Fernando Ortiz (1881-1969), a quien Lino Novás Calvo y Pérez Firmat llaman “Mr. Cuba”, y así también se titula el segundo capítulo de My Own Private Cuba (25). Ortiz, miembro de la Cámara de Representantes de la nación, está incluido con Enrique José Varona, Ramiro Guerra y Jorge Mañach, como uno de los cuatro pensadores más importantes del período repúblicano (Pérez Firmat, "Las consecuencias” 3). Consciente del estilo ensayístico de Ortiz, Pérez Firmat usa la misma expresión verbal en inglés, shied away, que usaba aquél para caracterizarse a sí mismo y describir su actitud hacia la escritura, “[...] Ortiz was not always very scientific. Or at least, he was not simply scientific, for he never shied away from flights of fancy or outbursts of humor" (My Own Private Cuba

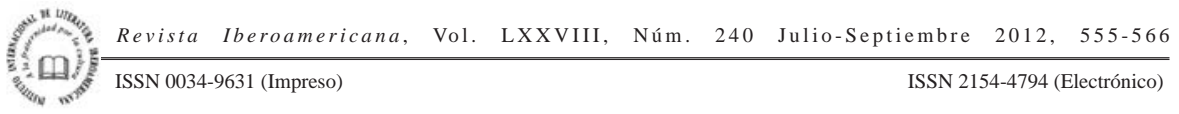


27). Aunque no escribió novelas ni poemas, Pérez Firmat lo considera el escritor criollista más importante de Cuba por sus ensayos (29). Basándose en las normas establecidas por este pensador cubano, Pérez Firmat continúa y refuerza sus ideas, mientras incorpora los cambios y las diferencias que han resultado de cincuenta años de exilio. Se nutre de todo un menú de cubanismos para definir la cultura cubana, y sigue remontándose a estos mismos símbolos para definirse a sí mismo. En My Own Private Cuba no se limita a un ensayo sobre Ortiz, sino que se explaya con cinco: "The Cuban Condition”, "Mr. Cuba”, "The Politics of Enchantment”, “Cuban Counterpoint” y “The Philological Fictions of Fernando Ortiz”. Es una acción típica del ensayista terminar un ensayo y continuarlo en otra ocasión. Como el propio Miguel de Unamuno acostumbraba a decir, "Más de esto otra vez" (133). Al igual que Unamuno, Pérez Firmat sigue este método de encadenar ensayos sobre Ortiz como si fueran capítulos en la pauta de Gómez-Martínez, “los sucesivos ‘capítulos' son en realidad nuevos ensayos” (35).

Algunas imágenes con las que juega Pérez Firmat son representativas de las transiciones culturales que son propiedad del ensayo: una de las más frecuentes que proviene de Ortiz es “ajiaco". Cuando los desterrados físicamente se mudan de un país a otro, como es el caso de los exiliados cubanos como Pérez Firmat, una de las cosas más añoradas es la comida del lugar que dejaron. Si tienen acceso a los ingredientes, pueden, por lo menos, continuar preparando y comiendo las recetas de allí, manteniendo así física y simbólicamente la cultura ausente. Aunque un nieto deje atrás a su abuela, puede seguir comiendo el ajiaco criollo o el pan de abuela aderezados en el nuevo país. Pérez Firmat explica el concepto de ajiaco, que viene de un ensayo de Fernando Ortiz de 1940, "Los factores humanos de la cubanidad":

he proposes a homey metaphor, the ajiaco, a stew of Amerindian origin that for Ortiz constitutes the culinary emblem of Cuba. He justifies the metaphor in a number of ways. First, since the ajiaco is made by combining a variety of meats and vegetables (whichever ones happen to be available), it conveys the ethnic diversity of Cuba. Second, the ajiaco is agglutinative rather than synthetic; even if the diverse ingredients form part of a new culinary entity, they do not lose their original flavor and identity. So it is with Cuba, where each ethnic or cultural component has retained its identity, where the mixture of cultures has not led to a neoculturative synthesis. (My Own Private Cuba 33)

A diferencia de la trillada metáfora del crisol (melting pot) de los Estados Unidos donde todos pierden su identidad para formar un producto metalúrgico destinado para fortificar la industria y la ética del trabajo, el ajiaco de Ortiz es una combinación de ingredientes que retienen su diversidad e individualismo. Se juntan para nutrir al cuerpo entero. Pérez Firmat percibe otros dos factores esenciales:

Third, an ajiaco is indefinitely replenishable, since new ingredients can be added to the stew as old ones are used up. In this respect, this dish symbolizes the continuing

\footnotetext{
Revista Iberoamericana, Vol. LXXVIII, Núm. 240 Julio-Septiembre 2012, 555-566 ISSN 0034-9631 (Impreso) ISSN 2154-4794 (Electrónico)
} 
infusion of new elements into the Cuban cultural mix, those "continuous transmigrations" that he mentions in the other essay. Lastly, ajiaco is itself an onomastic ajiaco, since it combines the African name of an Amerindian condiment, the ají or green pepper, with a Spanish suffix, -aco. (My Own Private Cuba 33)

No podemos pasar por alto la traducción de ají (green pepper) que Pérez Firmat emplea aquí sin por lo menos clarificar que la palabra ají también -o preferiblemente-se refiere a pimientos rojos y hasta picantes. Asimismo puede tener raíz española, relacionada al ajo y al ajillo (chili pepper). Inclusive hay versiones de ajiaco que se preparan con una sobredosis de ají y de ajo -que resultan en un ajiaco aún más picante. Así, podemos aumentar la metáfora del ajiaco a un nivel más gastronómico, y a la vez subrayar su conexión con la tierra misma. El ajo es un rizoma, desarraigado de la tierra que, por extensión, amplifica su descripción de una diáspora transplantada. El ajiaco es la imagen concreta del concepto teórico de transculturación. Pérez Firmat y Ortiz insisten en que esta transculturación no es una fusión, sino una cocción:

Lo característico de Cuba es que, siendo ajiaco, su pueblo no es un guiso hecho, sino una constante cocedura. Desde que amanece su historia hasta las horas que van corriendo, siempre en la olla de Cuba es un renovado entrar de raíces, frutos y carnes exógenas, un incesante borbor de heterogéneas sustancias. De ahí que su composición cambie y la cubanidad tenga sabor y consistencia distintos según sea catado en lo profundo o en la panza de la olla o en su boca, donde las viandas aún están crudas y burbujea el caldo claro. ("Factores” 169)

En el espíritu temático de nuestra colección de ensayos hace falta reconocer la continuidad de la metáfora del ajiaco misma. Ortiz la creó en su ensayo seminal, “América es un ajiaco” en 1940, y Pérez Firmat empieza a ensayarlo en los años noventa. Reconoce su deuda para con Ortiz por los conceptos de transculturación y ajiaco, y emplea los dos a propósito:

Two of Ortiz's notions, in particular, will play a prominent part in my discussion: transculturación, Ortiz's term for the translational displacements that generate vernacular culture: and ajiaco, his metaphor for the outcome of these displacements. During the course of my discussion I will repeatedly return to these two concepts, which will be the dominant ingredient in my own critical stew. (My Own Private Cuba 21)

Durante sesenta y ocho años, hasta 2008, se ha cocinado y prolongado la imagen del ajiaco. En una reseña muy reciente, titulada "Las consecuencias del amor por Cuba", Pérez Firmat revive la metáfora para describir la transculturación explicada por Ortiz:

\footnotetext{
Revista Iberoamericana, Vol. LXXVIII, Núm. 240 Julio-Septiembre 2012, 555-566 
La cubanidad es proceso y no producto. Ávido de neologismos, Ortiz troquela una palabra -transculturación- y acude a una metáfora -el ajiaco- para nombrar esta realidad en flujo. La transculturación designa la mezcla, mas no la síntesis, de culturas. El ajiaco, plato criollo preparado con ingredientes de la tierra, se distingue por su falta de finalidad, lo que Ortiz llama su "constante cocedura" (a medida que la caldera se vacía, se añaden más ingredientes). (4)

A riesgo de cometer una perogrullada, aquí subrayo que la imagen del ajiaco es una metáfora común para el proceso complejo de transculturación. Estos dos ensayistas están cumpliendo al pie de la letra la función principal que describió Mead hace sesenta años: siguen siendo “comentaristas de la cultura en sus transformaciones” (127).

Visto ya uno de los temas principales de Ortiz y Pérez Firmat, examinemos ahora algunas de las técnicas ensayísticas que emplean. AOrtiz le encanta emplear metáforas de comida - una cosa común con fuertes conexiones conscientes y subconscientes culturales para explicar un concepto antropológico-. Por ejemplo, describe la combinación de rasgos heredados como "arroz y frijoles” y dice que la etimología francesa de la palabra "guayabo" en el Diccionario de la Academia no vale una guayaba (Catauro 43). "De cualquier pretexto puede nacer un ensayo”, nos aconseja José Luis Gómez-Martínez, precepto que sigue siendo el pan nuestro de cualquier ensayo, "es precisamente lo cotidiano, lo ignorado por su continua presencia" lo que proporciona el punto de partida para reflexionar sobre asuntos transcendentales y eternos (80).

Es una característica común de Ortiz y Pérez Firmat el extender la metáfora a través de toda una lista de vocabulario relacionado con la metáfora central. Ortiz, en los dos párrafos contiguos en "Los factores humanos de la cubanidad" aumenta el impacto de la metáfora del ajiaco con una acumulación constante de palabras de comida: "buscarla (la cubanidad) en esa salsa de nueva y sintética suculencia"; "siendo ajiaco, su pueblo no es un guiso hecho, sino una constante cocedura"; "en la olla de Cuba es un renovado entrar de raíces, frutos y carnes exógenas, un incesante borbor [...]"; "la cubanidad tenga sabor y consistencia distintos según sea catado en lo profundo o en la panza de la olla o en su boca, donde las viandas están crudas y burbujea el caldo claro" (169; énfasis mío).

Asimismo, Pérez Firmat se contagia con esta tendencia de amontonar palabras que extienden la metáfora. El mantener una metáfora prolongada a través de toda una serie de palabras relacionadas puede ser exitoso solo si la correspondencia sostiene la argumentación en los dos niveles. En este sentido es la "estilización artística de lo didáctico [lo] que hace del ensayo una disertación amena en vez de una investigación severa y rigurosa" (Gómez-Martínez 20). Empero, a mi juicio, llega a un extremo de veras “arrebatado" (palabra favorita de Pérez Firmat), convirtiéndose en juego de palabras en vez de técnica aumentativa. Tal “disertación amena” deja de serlo con la última oración

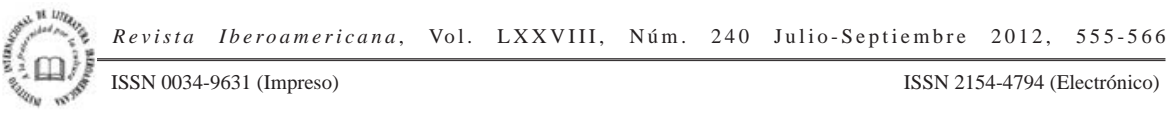


del párrafo de Pérez Firmat, que es más chistosa que didáctica, una conclusión que, en sí, acaba por ser "half-baked”:

The essence of Cuba [...] lies in that "constante cocedura”, in the incessant simmering of the ajiaco, an image that denotes the lack of a stable, enduring core of cultural indicia. Cuba is always cooking. Cubans are always cooking. Occupying a liminal zone or "impassioned margin" where diverse cultures converge without merging, Cuba lives in a trans- in a trance, in a transcurso. In Cuba, transience precedes essence. In Cuba, the raw and the cooked give way to the half-baked. (My Own Private Cuba 35)

Una ilustración mucho más amena y complicada de cómo Pérez Firmat continúa y aumenta la técnica de las metáforas extendidas de Ortiz se encuentra en la Introducción de My Own Private Cuba. Otra vez, se basa en la acumulación de vocablos relacionados con la comida. Ortiz describe su estudio La africana de la música folklórica de Cuba de 1950 en términos dulces, "pasta de guayaba hecha con azúcar sin refinar pero mechada con finas jaleas” (xv; énfasis mío). La comparación ortiziana de la música folklórica con una comida intensamente cubana enfatiza la raíz común de la cubanidad compartida por las dos. Aún más genial, está haciéndolo con una descripción sinestésica. Como sabemos, la sinestesia comunica una sensación (el oír música) en términos de otra (el saborear la dulce pasta de guayaba).

Consciente de la metáfora extendida, Pérez Firmat agrega más ingredientes cubanos, sabrosos y sinestésicos.

Drawing out Ortiz's fruity metaphor and indulging in my own bit of etymological fabulation, I would suggest that, in Ortiz's writings, knowledge is supplemented not by wisdom but by savvy, a term that I connect not just to saber but also to sabor. Ortiz's scholarship mixes saber and sabor; it testifies to "un sabor que es casi una sabiduría”, a phrase with which José Lezama Lima described Cuban coffee but that is equally applicable to Ortiz's brand of Cuban studies. If wisdom is the fruit of knowledge, savvy is its jalea. (4) [Como aquí Pérez Firmat emplea letra bastardilla para énfasis, yo he subrayado algunas palabras adicionales que incorporan la comida y amplifican la sinestesia.]

Esta metáfora extendida funciona a cuatro niveles. Primero, sigue y aumenta lo comestible de la fruta y el sabor con un nuevo elemento bebible, el café; segundo, a la par, hace hincapié en la cubanidad con el producto sui generis más cubano posible, el café y con el poeta cubano, Lezama Lima (también, curiosamente, el nombre de una fruta); tercero, con el café introduce una triple sinestesia de "gustos", combinando el sonido de la música, con el paladear de la jalea, con el aroma del café. Fácilmente podríamos admitir que los otros dos sentidos del tacto y de la vista están también alerta en este dibujo de (“drawing” out) la metáfora. Saturados ahora con los cinco sentidos físicos en

\footnotetext{
Revista Iberoamericana, Vol. LXXVIII, Núm. 240 Julio-Septiembre 2012, 555-566 ISSN 0034-9631 (Impreso) 
una sinestesia elevada a la quinta potencia, estamos preparados para percibir el cuarto nivel metafórico de este párrafo, la combinación de saber y sabor. Lo que a primera vista parece ser un simple juego de dos palabras con solamente una letra distinta, inspirado en parte por Lezama Lima, de repente se convierte en algo universal. Semejante acto de construir una metáfora empezando con algo descriptivo -y además totalmente cotidiano como la comida-y elevarlo a un nivel cósmico, espiritual y universal se clasificaría como una "metáfora visionaria" en los términos del teórico de la poesía y poeta también él, Carlos Bousoño (99-104). Estamos llegando casi a la "imagocracia” lezamiana misma, donde la única fuerza capaz y merecedora de regir es la imagen poética. Percibimos lo que yo sólo puedo denominar una "supersinestesia", a falta de una figura retórica más precisa. Así como la sinestesia describe la percepción de un sentido en términos de los otros, aquí los cinco sentidos físicos se unifican y perciben en términos de un sentido "no-físico" -el "sentido" común, que es todo salvo común- la sabiduría, o la "fruta" del árbol de la ciencia, en inglés, "the 'fruit' of the tree of 'knowledge'” (My Own Private Cuba 4).

El poder extender una metáfora visionaria a cuatro niveles de significado y a la supersinestesia no es propiedad del ensayo empírico, sino que nos conduce a la prosa poética. A la vez que Pérez Firmat evalúa lo que hace Ortiz, está definiendo su propio método, "It is impossible to read these works without the sensation that one is not only reading about Cuban literature but reading in Cuban literature" (My Own Private Cuba 5).

Otra técnica ensayística que Gustavo Pérez Firmat emula de Fernando Ortiz es el contrapuntear. Ortiz practica esta técnica en toda su obra, y más obviamente en un libro que, otra vez, incluye en su título una referencia a un producto comestible y otro producto sui generis cubano al máximo, Contrapunteo cubano del tabaco y el azúcar. De hecho, uno de los ejercicios más eficaces y constantes del contrapunteo en manos de Pérez Firmat en My Own Private Cuba es comparar y contrastar a Fernando Ortiz con Jorge Mañach. Si Ortiz admite su Yo en el ensaYO, Mañach, también uno de los cuatro pensadores cubanos republicanos más importantes ya mencionados, mantiene un tono magisterial y reservado. Explica Pérez Firmat:

Jorge Mañach and Fernando Ortiz, two figures to whom I will return repeatedly in this book, illustrate two contrary views of this relation. Mañach, who liked to quote Christopher Morley's statement that we have to become foreigners in our own country to see it properly, believed in the importance of critical distance, in the detachment of the intellectual yo from his scholarly canción. As he once put it, "La crítica -valga lo que valiere- necesita siempre de distancia, un ámbito de soledad, libre de todas las coacciones de la espectación o la simpatía”. (1)

Revista Iberoamericana, Vol. LXXVIII, Núm. $240 \quad$ Julio-Septiembre 2012, $555-566$
ISSN 0034-9631 (Impreso) 
Al evaluar a Ortiz, Pérez Firmat observa que él no busca “magisterio”, sino "sabiduría”, haciéndonos constar, otra vez, del valor de la fruta de la sabiduría ya versada como una de las metas de Ortiz:

Yet Ortiz, whose expertise in nearly all facets of Cuban culture was unmatched by any of his contemporaries, seldom adopted the magisterial pose. Unlike Mañach, he did not presume distance or detachment; his characteristic mode was celebration rather than censure. [...] Never an impartial or innocent bystander, Ortiz makes no attempt to disengage his own discourse from that of its objects. (My Own Private Cuba 3)

La unión ya vista en la metáfora saber/sabor se divide ahora para contraponer el estilo de Ortiz (“Ortiz’s scholarhip mixes saber and sabor”), mientras que Mañach es sólo saber:

The opposition between Mañach's saber and Ortiz's sabor gives us a context in which to understand a noticeable trend within literary studies in general. Following Ortiz, some of the most significant recent work on Cuban literature and culture renounces the voice of mastery in favor of the voice of knowledgeable but nonmagisterial assertion. (My Own Private Cuba 4-5)

Al contrapuntear los ensayos de Mañach y Ortiz, y otros cubanos importantes en My Own Private Cuba, Pérez Firmat no sólo crea su propia visión de Cuba, sino que autodefine su propio estilo como ensayista. Admite que estos ensayos son una tentativa de fundir su agenda de investigación con su escritura, "fuse a research agenda with a writing program” (6). Lo que hace a su propia Cuba suya, es ponerse a sí mismo en su propia escritura, "That was when I realizad that it was posible to bring my life to my work in ways that improved my life and made my work more livable" (7). Gustavo Pérez Firmat reitera el epígrafe de Bola de Nieve que abre el libro, "Yo soy la canción que canto” (1).

Uno de los principios sobre el cual teoriza Gómez-Martínez es que “el ensayo es una forma de pensar” (55). Para Gustavo Pérez Firmat, no solo es una forma de pensar, sino que es una forma de entender su yo, de ser la canción que canta, y de insertarse en el ensaYo. Mediante este proceder o método vemos que Pérez Firmat cumple con la definición de hace medio siglo de Robert G. Mead, de “comunicar los conceptos o meditaciones personales de una manera lírica” (127), y con la de Michel E. Montaigne de hace más de cuatro siglos, "Estas son mis fantasías, en las cuales yo no trato de dar a conocer las cosas, sino a mí mismo” (Oeuvres complètes 387). Pérez Firmat no solo estudia y enseña las tradiciones peninsulares académicas, sino que continúa, aprehende y aprende de la tradición ensayística cubana, especialmente aquella establecida por Fernando Ortiz en la primera mitad del siglo xx, y por medio de su perspectiva diferente como cubano-americanista describe y vive la "cultura en sus transformaciones.”

\footnotetext{
Revista Iberoamericana, Vol. LXXVIII, Núm. 240 Julio-Septiembre 2012, 555-566 ISSN 0034-9631 (Impreso) 
Austin, Elisabeth. "Pérez Firmat, Gustavo. Vidas en vilo: la cultura cubanoamericana". Hispanic Review 73/1 (invierno 2005): 122-23.

Bousoño, Carlos. Teoría de la expresión poética: Hacia una explicación del fenómeno lírico a través de textos españoles. Madrid: Gredos, 1962.

Gómez-Martínez, José Luis. Teoría del ensayo. Salamanca: U de Salamanca, 1981. Lezama Lima, José. La expresión americana. La Habana: Letras Cubanas, 1993.

Mead, Robert G. Breve historia del ensayo hispanoamericano. México: Andrea, 1956. Montaigne, Michel E. Oeuvres complètes. Albert Thibaudet y Maurice Rat, eds. Bruges: Bibliothèque de la Plèiade, 1967. [En el ensayo número 50 del libro primero, De Democritus et Heraclitus, Montaigne explica las características de sus ensayos].

Onís, José de. "La significación del ensayista en las Américas". Hispania 45/3 (sept. 1962): 443-45.

Ortega y Gasset, José. Estudios sobre el amor. Madrid: Espasa-Calpe, 1966. Notas. Madrid: Espasa-Calpe, 1967.

Ortiz, Fernando. “América es un ajiaco”. La Nueva Democracia 21/11 (1940): 20-24. Un catauro de cubanismos. Habana: [sin editorial], 1923. Contrapunteo cubano del tabaco y el azúcar. Habana: J. Montero, 1940.

Pérez Firmat, Gustavo. "Las consecuencias del amor por Cuba”. Reseña de Motivos de Anteo: Patria y nación en la historia intelectual de Cuba, de Rafael Rojas. Primera Revista Latinoamerciana de Letras 1/6 (oct.-nov. 2008): 3-5. Idle Fictions: The Hispanic Vanguard Novel 1926-1934. Durham: Duke UP, 1982. Life on the Hyphen: The Cuban-American Way. Austin: U of Texas P, 1994. [versión española: Vidas en vilo: la cultura cubanoamericana. Madrid: Colibrí, 2000]. Literature and Liminality: Festive Readings in the Hispanic Tradition. Durham: Duke UP, 1986.

My Own Private Cuba: Essays on Cuban Literature and Culture. Boulder: SSSAS, 1999.

Next Year in Cuba: A Cubano's Coming-of-Age in America. Nueva York: Anchor Books, 1995. [versión española: El año que viene estamos en Cuba. Houston: Arte Público, 1997].

Tongue Ties: Logo-Eroticism in Anglo-Hispanic Literature. Nueva York: Palgrave MacMillan, 2003.

Unamuno, Miguel de. El porvenir de Españaylos españoles. Madrid: Espasa-Calpe, 1973.

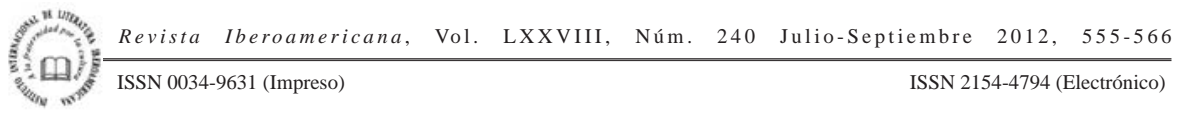

